\title{
¿Cómo aprovechamos la innovación tecnológica los países del Tercer y Cuarto Mundo?
}

\section{How The Third And Fourth World Countries Take The Technological Innovation?}

Claudia Nacif Muckled*

\section{Resumen}

El documento es un ensayo reflexivo y propositivo sobre el libro "Las conexiones ocultas", de Fritjof Capra. En él se plantea el aprovechamiento de la "innovación tecnológica”, rescatando este concepto como la mejor práctica de la globalización. Se plantea este tema como un desafío de las universidades para transformar el proceso enseñanza-aprendizaje desde la lógica de la "alfabetización tecnológica" como punta de lanza para desarrollar líneas de investigación aplicadas e interdisciplinarias tomando como foco central la "lucha contra la pobreza”, con el objeto de atenuar los efectos adversos que trajo consigo la globalización en la base de la pirámide social, sobre todo de los países del Tercer y Cuarto Mundo.

Palabras clave: Innovación tecnológica, alfabetización tecnológica, alfabetización ecológica, lucha contra la pobreza, globalización, ecodiseño, pirámide social, responsabilidad social universitaria, transformacional, autopoiesis.

\begin{abstract}
The document is a thoughtful and purposeful essay on the book "The hidden connections" of Fritjof Capra. He raises the use of "technological innovation" rescuing this concept as a
\end{abstract}

Vicerrectora Administrativa Financiera Nacional. Universidad Católica Boliviana San Pablo. 
best practice of globalization. This question as a challenge to the universities to transform the learning process from the logic of the "technological literacy" as a spearhead to develop applied and interdisciplinary research lines taking the 'fight against poverty' as the central focus, in order to mitigate the adverse effects brought about by globalization to the base of the social pyramid, especially in the third and fourth world countries.

Keywords: Technological innovation, Technological literacy, Literacy ecological, Fight against poverty, Globalization, Eco-design, Social pyramid, University social responsibility, Transformational, Autopoiesis

\section{Introducción}

El Dr. Fritjof Capra desarrolla en Las conexiones ocultas ${ }^{1}$ un marco conceptual que integra las dimensiones biológicas cognitivas y sociales de la vida frente a algunas cuestiones criticas de nuestros días, como son los efectos de la globalización, y predice con sólida argumentación el inicio del fin del capitalismo representado en su máxima expresión por la globalización económica mundial, concretamente con una probable derrota ante la confrontación con las dos alternativas claras de reconducción del capitalismo: la "alfabetización ecológica" y el "ecodiseño".

Sin embargo, considero que el supuesto de la destrucción gradual de la globalización está aún muy lejano de la realidad. En el presente ensayo desarrollaré argumentos que me motivan a plantear una alternativa adicional que considere los importantes efectos positivos de la globalización y de la era de la información, como lo es la innovación tecnológica. Concretamente, mi postulación es la "alfabetización tecnológica" como instrumento de concientización complementaria a la "alfabetización ecológica” y al "ecodiseñó".

En primer lugar desarrollaré los elementos relevantes que utiliza el autor para introducirnos a las postulaciones acerca del origen de la vida, haciendo hincapié en la autogénesis o autopoiesis, respaldada por la Teoría de Santiago, donde la red metabólica es el origen de la vida, indicando que donde hay vida hay redes. Seguidamente esbozaré propiamente las tres teorías del origen de la vida a través de la mutación, las bacterias y la simbiosis. Al tratar de explicar estas tres vías se encuentra relación con el concepto de qué es la vida. La dimensión social de la conciencia y la similitud de los humanos con los chimpancés, utilizando experimentos a

1 2003. España: Editorial Anagrama. 
través de la expresión y comunicación del lenguaje corporal y por señas para llegar al lenguaje (ASL), evidencian que existe estrecha relación de aprendizaje entre ambos.

Destacaré la relevancia con la que sostiene el autor la interpretación de la dimensión social y el rol de la consciencia y la espiritualidad para conducir hacia el concepto de pertenencia cultural e identificación de las normas de conducta y valores aceptados por la cultura y el entorno de los humanos. Hare hincapié en el valor ético de la conducta humana como un mecanismo de concientización y sensibilización de los efectos del imperio de las grandes corporaciones globales patrocinadas por las instituciones de Bretton Woods, como el Banco Mundial (BM), el Fondo Monetario Internacional (FMI) y la Organización Mundial del Comercio (OMC).

Seguidamente argumentaré que, tomando en cuenta el principal beneficio de la globalización, que es la innovación tecnológica, se puede consolidar el pensamiento de los defensores de la tecnología al indicar que su efecto puede ser neutral, dependiendo de cómo se la utilice. Desestimando los efectos negativos de la tecnología, se puede pensar en una alternativa real de desarrollo transformacional, la "alfabetización tecnológica” y los alcances de ésta para un futuro sostenible enmarcado en el concepto de "vivir bien".

Desarrollaré a continuación el rol de los ejecutivos y líderes de las empresas en mercados financieros altamente volátiles y el deseo que los mueve por maximizar el precio de las acciones antes de maximizar el beneficio. Ante estos efectos adversos de la globalización sobre el ecosistema, el medio ambiente y la conducta humana, con la pérdida de valores y principios, esbozaré las alternativas y movimientos organizacionales planteados por el autor que se desarrollan en el mundo para hacer frente al capitalismo y a la incidencia de las transnacionales tanto en el área económica, política, social y cultural como en el área de la biotecnología y la genética modificada (GM). Finalizaré el cuerpo del ensayo narrando el inicio de la "Coalición de Seattle" como la base principal para el surgimiento de corrientes de pensamiento en contra de los efectos de la globalización y las alternativas concretas de alfabetización ecológica y ecodiseño, que desarrolla el autor.

En las conclusiones se reflejará una síntesis de los puntos centrales de este libro, para culminar con una breve descripción de los argumentos planteados en el cuerpo del ensayo a favor de la "alfabetización tecnológica" como una alternativa complementaria para cultivar inteligentemente los beneficios de la innovación tecnológica producida por el fenómeno de la globalización. 


\section{Nudo o cuerpo}

El autor comienza su narración de la vida indicando que todos los organismos vivos están conectados y que ninguno de ellos puede vivir de manera aislada, en concordancia con la autogénesis definida, por Maturana y Varela, como "autopoiesis", que significa "que se hace a sí misma”.

Toda vida humana consiste en células, cada una de las cuales contiene dos clases de macromoléculas: proteínas y ácidos nucleicos $(\mathrm{ADN})$ y ácido ribonucleico (ARN). Los sistemas vivos contienen $\mathrm{ADN}$ pero también la contienen las moléculas muertas, porque el $\mathrm{ADN}$ puede permanecer por cientos y miles de años después que un organismo vivo muere.

Como señala Pier Luisi, "uno de los enfoques de vida está centrado en el ADN y el otro enfoque está centrado en la célula”. Retomando el principio de la autogénesis señalada en párrafos precedentes, las células componen una red metabólica que da origen a la vida y a partir de este concepto de red se explica la red celular o autopoiesis. La segunda teoría es la evolución prebiótica, que se refiere a la evolución molecular de la materia inanimada que anteriormente debió haberse iniciado de energía de células vivas. La red celular es material y energéticamente abierta e incluye un flujo importante de materia y energía para reproducirse, regenerarse y perpetuarse.

Morowitz, en su libro Beginnings of cellular Life, aborda la evolución prebiótica desde dos ángulos: a) la identificación de principios básicos de la búsqueda de la biología molecular comunes a todas las células vivas -principio de evolución, y b) la existencia de burbujas de vida mínimas, que refleja que existen pequeñas moléculas presentes en la complejidad molecular.

En el desarrollo de la vida planteado por Morowitz se indica que "no sabemos cuántos orígenes independientes de la vida celular hayan podido darse, pero no cabe duda de que cualquier forma presente de vida desciende de un clon único que es un antepasado universal que supero a todas las protocélulas".

El autor desarrolla tres vías de evolución de la vida: a) la mutación aleatoria genética, que es una pieza importante de la teoría neodarwiniana que sale del $\mathrm{ADN}, \mathrm{b}$ ) las bacterias, que tienen capacidad de acumular mutaciones aleatorias junto con grandes fragmentos de ADN a través del intercambio de genes, y c) la simbiosis, que es la creación de la vida por acomodos simbióticos permanentes. 
En el libro, el autor describe "La teoría de Santiago de la cognición", que define la cognición o proceso de conocimiento como proceso mismo de la vida, proceso vital que incluye percepción, emoción, y comportamiento, y no requiere la existencia de un cerebro ni sistema nervioso.

La teoría de Santiago esta relacionando la cognición con la autopoiesis o proceso de autogénesis de las redes vivas. La clave de la teoría de Santiago es que el sistema vivo mantiene la libertad de decidir a qué debe prestar atención y qué es lo que lo va perturbar. La descripción de Santiago de la cognición incluye el concepto de alma o espíritu como el "soplo de la vida"; la separación de la relación entre mente y materia implica que la mente es un proceso de cognición y no es sustancia

Para explicar la relación entre cognición y consciencia se hace referencia en una triangulación a la experiencia consciente de la física y la química del sistema nervioso y de la dinámica no lineal de las redes neuronales. Santiago demostró que la cognición es el "alumbramiento" de un mundo a través del proceso de vivir.

Por tanto, el estudio de la consciencia es fundamental para entender la libertad de los seres humanos expresada en sus actitudes. Se detallan cuatro escuelas de estudio de la consciencia: la tradicional, que es la escuela "neuroreduccionista", dado que reduce la consciencia a mecanismos neuronales; el "funcionalismo", que es la escuela más popular, donde los estados mentales están definidos por su organización funcional de relaciones causales del sistema nervioso; los "misterianos", que es la corriente menos conocida, donde la consciencia constituye un misterio profundo que nunca se podrá develar, y la cuarta escuela es la "neurofenomenología", que constituye un enfoque de estudio de la consciencia que combina la experiencia consciente con el análisis de patrones y procesos neurales; es un planteamiento dual.

Se aborda en el libro la importancia de la dimensión social de la consciencia, reflejando que la consciencia no es un fenómeno meramente biológico sino también social, por tanto, el relacionamiento social está basado en el lenguaje, que es el mecanismo básico de comunicación. Se han realizado investigaciones de comunicación con chimpancés mediante el lenguaje gestual, provocando una nueva forma de pensar acerca del lenguaje humano. Estas investigaciones demuestran que el ADN de hombres y chimpancés tienen una diferencia genética de $1.6 \%$. 
Hay demasiadas similitudes entre humanos y chimpancés tanto en lo social, cultural como en sus anatomías; estudios demostraron que existe relación en el lenguaje, que los chimpancés no solo dan gritos sino que mueven sus manos y se comunican entre ellos con gestos absolutamente correctos. Éste es el lenguaje hablado conocido como ASL (lenguaje de sordomudos, que utiliza signos).

Roger Fouts, en su libro The next of Kin, interpreta el origen del lenguaje "como la comprensión de la capacidad conjunta de chimpancés y su relación con los humanos”. El habla habría evolucionado a partir de la capacidad de la "sintaxis" (igual que los chimpancés), y la sintaxis encierra gestos, herramientas, códigos, símbolos y tecnología.

Dentro de todo este escenario de explicación de la vida, de la consciencia y de la dimensión social que explica la naturaleza de las relaciones sociales a través de la comunicación, se debe añadir una variable mas para entender el comportamiento y las actitudes del ser humano: el espíritu o espiritualidad, definido como una creencia "mística, religiosa o espiritual" que nace de una determinada experiencia profunda de la realidad.

Como la vida pertenece al universo, no puede estar disociada nunca de la materia, por ello se narra en el libro la existencia de cuatro perspectivas: la forma (red celular), el proceso (reacciones químicas), la materia (componente de la célula) y el significado (comprensión de la realidad social que está ligada a la de la consciencia reflexiva).

Se presenta una figura gráfica de un tetraedro que integra estas cuatro perspectivas, para contribuir a la comprensión del fenómeno social; relacionado con ello, Aristóteles afirma que existen cuatro perspectivas las internas que son materia y forma y las externas que son la eficaz y la final. Para el Dr. Capra, la causa final es el significado.

En función de las cuatro perspectivas señaladas anteriormente, se puede decir que la acción pertenece a la perspectiva del "proceso". Habermas conecta la perspectiva del proceso con las otras tres:

la acción instrumental tiene lugar en el mundo exterior (materia), la acción estratégica se desarrolla en el terreno de las relaciones humanas (forma) y la acción comunicativa se conecta al logro de la comprensión (significado). Cada clase de acción está relacionada con un sentido de rectitud, la recta acción se refiere a la verdad de los hechos en el mundo material, a la rectitud moral en el mundo social y a la sinceridad en el mundo interior. 
Hasta aquí hemos sintetizado que la red constituye un patrón de organización básico para todos los sistemas vivos desde redes metabólicas celulares hasta las cadenas del ecosistema. Extender la comprensión del sistema de la vida al ámbito social significa aplicar a la realidad nuestros conocimientos de patrones y principios de organización básicos de la vida, concretamente, nuestra comprensión de las redes vivas.

El autor prefiere mantener el concepto de autopoiesis como característica definitoria de la vida, pero en su análisis de organizaciones humanas sugiere también que los sistemas sociales pueden estar vivos en grado variable; es de esperar un doble efecto de las redes de comunicación: 1) generan ideas y contextos de significado y 2) generan normas de comportamiento (definido como estructuras sociales).

En este marco del doble efecto de las redes de comunicación, la independencia de los seres vivos no debe ser confundida con su autonomía, lo que verdaderamente es cierto es que los seres vivos habitan en un entorno y no están por ningún motivo aislados de ese entorno, más bien viven conectados a él y su comportamiento es autodeterminado, y por ende libre. Esa libertad que tenemos los seres humanos nos permite formular valores y normas sociales de comportamiento que se enmarcan dentro de nuestra propia cultura, cultura que nos genera un sentido de pertenencia con sus valores, creencias y normas de conducta.

Esta red social enmarcada en la cultura proporciona la identidad para que las personas recreen y renegocien continuamente, al igual que la red metabólica celular que recrea constantemente el entorno de la membrana celular que le da su propia identidad.

Si hablamos de identidad cultural, que es la red social en la que se desenvuelve el individuo, debemos introducir el concepto de poder como un fenómeno natural de la realidad social. Como señala el economista Galbraith en The anatomy of Power, el rol del poder en la organización social está ligado a posturas de intereses personales que conllevan a conflictos de intereses colectivos, pero también es el propio poder el mecanismo para que se resuelvan estos conflictos.

Vivimos en la actualidad en un mundo globalizado que es cada vez más exigente con las nuevas formas de organización social que recaen en las estructuras organizativas; los líderes de estas organizaciones son quienes tienen el poder y la autoridad para encontrar mecanismos de solución de conflictos de interés y tomar las decisiones correctas. 
Estas organizaciones sociales, tales como empresas o instituciones políticas, son sistemas cuyos patrones de organización están diseñados para distribuir el poder. Estos patrones fundamentales diseñados se denominan estructuras organizativas y están representadas visualmente por organigramas estándares, es decir, representados por normas de conducta que facilitan la toma de decisiones y encarnan las relaciones de poder. Estas normas de conducta son las que se denominan propiamente "estructuras sociales"; podemos interpretar con claridad que las mismas constituyen "la cultura de la red". El autor enfatiza esta idea en la que el conjunto de empresas y organizaciones que forman los sistemas sociales producen estructuras tanto materiales como no materiales.

En la actualidad, las estructuras materiales se hacen más representativas y relevantes con el avance de la tecnología. El origen de la tecnología se enmarca con la historia de la evolución humana: los gestos, el lenguaje, las herramientas, los equipos y maquinarias son producto de la innovación tecnológica.

Todas las épocas de la historia desde la Edad de piedra hasta la Edad de la información, tienen que ver con cambios tecnológicos. Ésta es la razón fundamental para centrarme en este ensayo en la importancia de la innovación tecnológica y plantear como argumento principal el aprovechamiento inteligente de los problemas que ha generado en la actualidad la globalización en el área económica, política, social y ambiental; promoviendo una política de concientización para aceptar un nuevo modelo económico-social alternativo e inclusivo, basado en la estrategia de la "alfabetización tecnológica".

La "alfabetización tecnológica" implica encontrar, a partir de la innovación tecnológica, el diseño de políticas, estrategias y planes de acción concretos para beneficiar a la base de la pirámide social, que representa el $80 \%$ de la población mundial pero que concentra solo el $15 \%$ del ingreso, mientras que el $20 \%$ de la población mundial concentra el $85 \%$ de la riqueza:

\section{Distribución del ingreso Distribución del ingreso}

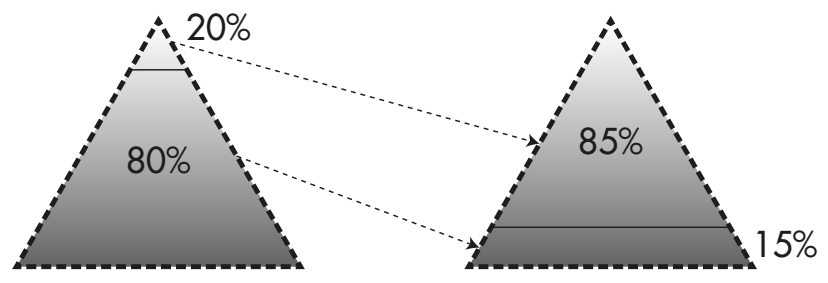


Cifras adicionales que nos proporciona el autor son verdaderamente reveladoras: "el 20\% más pobre de la población concentra el 1.4\% de la riqueza y el activo de las tres personas más ricas del mundo supera el PIB de los países subdesarrollados con sus 600 millones de habitantes".

De acuerdo al Coeficiente Gini, que representa el nivel de distribución de ingresos, donde el valor de cero (0) refleja que los ingresos y el consumo están distribuidos equitativamente entre toda la población, mientras que el valor de uno (1) representaría una situación hipotética en la que sólo una persona posee toda la riqueza, se estima que la desigualdad mundial es de 0.63; la renta del $20 \%$ de las personas más ricas del mundo es 28.7 veces más elevada que la del $20 \%$ más pobre.

En este contexto real, la "alfabetización tecnológica" hace bastante sentido cuando buscamos alternativas de solución frente a los efectos adversos de la globalización, utilizando la innovación tecnológica para promover concretamente la "estrategia de la lucha contra la pobreza” y estableciendo políticas que permitan beneficiar a la base de la pirámide social. Esto con el objetivo de acortar paulatinamente la brecha entre ésta y la élite de la pirámide por medio de emprendimientos tecnológicos medioambientales, ecológicos, sociales y productivos y con el aprovechamiento de la innovación tecnológica en la producción de software para desarrollar plataformas virtuales en línea en teleinformática y telemedicina.

La educación es el medio correcto para promover la "alfabetización tecnológica", las instituciones deformación académica, colegios yuniversidades tienen un reto extremadamente significativo y deben estar preparadas para el nuevo cambio social y económico a partir de la innovación tecnológica.

Es entonces, más relevante el rol de los gobiernos en el diseño de las políticas públicas para reconducir y establecer una reingeniería educativa o lo que comúnmente se denomina una reforma educativa, sobre todo en los países del Tercer y Cuarto mundo, que son los países donde se concentran los altos índices de pobreza. Como ejemplo concreto, en mi país, Bolivia, la pobreza alcanza al $60 \%$ de la población y el $25 \%$ de los habitantes viven en extrema pobreza, sobre todo en el área rural.

Me voy a referir concretamente al rol de las universidades y al desafío que deben trazarse para lograr, a través de la interdisciplinariedad, enfocarse en la "alfabetización tecnológica" para beneficiar a la base de la pirámide social. 
Las distintas disciplinas del conocimiento deben trabajar coordinadamente de manera transversal o interdisciplinariamente con el objetivo de llegar con políticas, estrategias y planes de acción concretos a la base de la pirámide social y no así a la elite de la pirámide (como se ha venido dando en la práctica con la globalización económica actual).

El logro de este objetivo implicará subrayar en los planes de estudio de las diferentes disciplinas las competencias pertinentes para alcanzar esta coordinación transversal para disminuir la pobreza en los países del Tercer y Cuarto mundo. A manera de ejemplificar, detallo a continuación algunas de estas estrategias o políticas para ciertas disciplinas:

- Ciencias sociales y humanas: diseño de políticas económicas y sociales.

- Arquitectura: construcción de viviendas sociales.

- Ingenierías: Diseño de innovaciones tecnológicas tales como el desarrollo de software en teleinformática y telemedicina.

- Administración y gestión: crear estrategias de emprendimiento: semilleros de empresas, incubadoras de empresas y aceleradoras de empresas.

- Ciencias jurídicas y políticas: consultorios jurídicos sociales.

- Psicología: consultorios psicológicos basados en temáticas como familias, toxicomanías, terapias breves, clínica y social.

- Educación y psicopedagogía: formación de los educandos con valores, ética y compromiso con la sociedad.

- Antropología: análisis de la interculturalidad y normas de conducta enraizadas en cada cultura.

- Ciencias de la salud: desarrollo de investigaciones para atacar enfermedades comunes de los países pobres, como son la tuberculosis, mal de Chagas y enfermedades tropicales.

Continuando con el rol relevante de las universidades para transmitir y generar conocimiento con la "alfabetización tecnológica", propongo algunas directrices en el marco de la Responsabilidad Social Universitaria (RSU):

- Focalizarse en el rol individual del ser humano y en su relacionamiento con su entorno más cercano: la familia, la comunidad, la sociedad y el país, asumiendo una actitud proactiva y de concientización de la responsabilidad de su accionar frente a los desafíos que enfrenta para ser partícipe en el cambio de nuestro futuro, para un "mejor vivir". 
- Trabajar en los valores, la ética y el compromiso del ser humano con la sociedad como una actividad principal de la Responsabilidad Social Universitaria

- El actor más importante es la persona en la sociedad, en la comunidad en la familia y en el plano personal de autoconocimiento y aceptación para trascender con su accionar en el bienestar colectivo.

- La universidad debe ser el centro de debate y de diseño de políticas para beneficiar a la base de la pirámide: parque tecnológico, territorios inteligentes, semilleros de ideas, incubadoras de empresas y aceleradoras de empresas.

- Concientización de que el futuro está en las decisiones que se tomen en función de las normas de conducta del comportamiento, la cultura, respetando el liderazgo y poder de los individuos conscientes del ejercicio de sus propias libertades y acciones. Estas decisiones deberían orientarse a la lucha contra la pobreza, al emprendimiento social y al emprendimiento productivo.

Debemos introducir una nueva concepción de la ciencia económica. Clásicamente, la economía es definida como la ciencia que estudia la asignación eficiente de los recursos escasos; actualmente se habla de que los recursos no son escasos sino más bien "inaccesibles". Por tanto, el reto se traduce en la manera que debemos utilizar la innovación tecnológica para hacer que los recursos sean accesibles, en otras palabras, lo que hace accesible a los recursos es la innovación tecnológica, generada por cambios tecnológicos.

Por ejemplo, el 2\% de la acumulación de agua en el planeta es agua dulce (recurso accesible) y el 98\% restante es agua salada (recurso inaccesible); con la innovación tecnológica se debe encontrar el mecanismo de desalinizar ese $98 \%$ de agua salada y convertirla en un recurso accesible para lograr la sostenibilidad ecológica del planeta, puesto que el agua es el recurso esencial para generar y perpetuar la vida.

Existen varios planteamientos, como el de Marx, que consideran que la llegada de la tecnología no ha sido necesariamente beneficiosa. Marx habla de la terrible explotación de los trabajadores en las industrias británicas del encaje y la porcelana; recientes tendencias hablan de las tensiones entre valores, culturas y alta tecnología.

Sin embargo, los defensores de la tecnología rechazan estas críticas e indican que la tecnología es "neutral", porque depende cómo la utilicemos y el uso que le demos para que sus efectos sean los deseables o por el contrario sean negativos para la sociedad. Personalmente 
comparto esta defensa de la tecnología al proponer como alternativa concreta para utilizarla beneficiosamente el comenzar por la "alfabetización tecnológica".

Acepto, absolutamente, que la globalización ha traído a las organizaciones y por ende a sus altos ejecutivos mayores exigencias de conocimiento para combatir los cambios y hacer frente a las turbulencias económicas, políticas y sociales a las que nos enfrentamos. Esto trajo como consecuencia la inestabilidad emocional y física en el personal de las organizaciones, desde sus altos ejecutivos hasta los niveles organizativos más bajos; es lo que constantemente denominamos estrés. El estrés afecta todo el entorno en el cual se desenvuelven los individuos, desde los planos personal, familiar y social hasta el institucional.

Entonces, la "alfabetización tecnológica" tiene mayor sentido si pensamos que vamos a proporcionar herramientas de concientización e instrumentos técnicos aprovechando la innovación tecnológica para educar tanto a los grandes empresarios, que mantienen el poder y el control de las organizaciones, como a todo el personal de las mismas. Estas técnicas y herramientas permitirán no solo agilizar los procesos y ordenarlos, mejorando la eficiencia corporativa, sino principalmente y como mayor efecto, se reflejarán en el individuo como ser humano. Por ejemplo, hablemos de la técnica de administración del tiempo. Esta herramienta podrá ser utilizada para asignar el tiempo necesario que se va destinar en el trabajo y para asignar el tiempo que requiere el individuo para encontrarse a sí mismo, así como para relacionarse con su entorno más cercano y accionar con normas de conducta éticamente correctas, dentro de su ambiente cultural.

La complejidad existente en las corporaciones industriales y tecnológicas para hacer frente a las turbulencias exige mayor grado de agilidad de respuesta; y esto se hace cada vez más exigente, por lo que el autor considera que se constituye en una amenaza al ecosistema al llevarnos a una probable destrucción medioambiental, así como hace visible la amenaza de la supervivencia de la humanidad. Por ello, el Dr. Capra plantea un "rediseño completo de nuestras tecnologías e instituciones sociales, así como salvar el abismo actual entre el diseño humano y los sistemas ecológicamente sostenibles de la naturaleza” (pág. 135).

El autor señala que las empresas necesitan cambios profundos tanto para adaptarse al nuevo entorno empresarial como para llegar a ser ecológicamente sostenibles. Este doble reto es real y urgente, y a ello se debe el planteamiento de que en la economía actual la gestión y la tecnología están ligadas a la creación de conocimientos. El aumento de la productividad no viene de la fuerza laboral sino de la capacidad de equiparla con nuevos conocimientos. Por 
tanto, "la gestión del conocimiento", el "capital intelectual" y el "aprendizaje organizativo" se han convertido en nuevos e importantes temas para la gestión empresarial.

En concordancia con estos planteamientos de Capra, encuentro mayor respaldo y coincidencia para aprovechar la innovación tecnológica en la era de la información y del internet para logar la "alfabetización tecnológica", que permita desde los centros mismos de generación y transmisión de conocimientos, como son las universidades, la capacitación y concientización tecnológica para los diferentes estamentos de las estructuras emergentes de la crisis actual, para orientarlos en el camino de un nuevo orden económico y social con innovación, flexibilidad y creatividad. El desafío actual de los líderes es encontrar el equilibrio, como señala el Dr. Capra, entre la creatividad de la emergencia y la estabilidad del diseño; un buen líder debe facilitar la emergencia, que significa facilitar la innovación y creatividad.

En el libro se hace referencia en varias oportunidades a que la globalización nace en la última década del siglo XX, insistiendo en que es un término utilizado para definir los extraordinarios cambios de la tecnología, información y redes; el proceso de globalización económica fue diseñado por los principales países capitalistas (llamadas las naciones de G7), por las corporaciones transnacionales y por las instituciones financieras globales creadas para ese propósito, dando origen a las grandes e influyentes instituciones de Bretton Woods, como son el Banco Mundial (BM), el Fondo Monetario Internacional (FMI) y la Organización Mundial del Comercio (OMC); sin embargo, el autor demuestra con rigor las consecuencias de tanto supuesto beneficio que se hicieron ver rápidamente con la desintegración social, la quiebra de la democracia, el deterioro más rápido del medio ambiente y la expansión de nuevas enfermedades y de la pobreza.

La situación más crítica, ocurrida recientemente con la crisis financiera mundial en septiembre del 2008, puso en evidencia la vulnerabilidad de las grandes innovaciones financieras que sustituyeron el papel moneda por contratos, como son las opciones de futuros, los fondos de inversión, los fondos de cobertura y los instrumentos financieros derivados. Esta innovación financiera con la virtualidad de los productos financieros se traduce en el objetivo de maximizar el valor de las empresas a través de la maximización del precio de sus acciones, pasando a un segundo plano la maximización del beneficio. Éste es un cambio sustancial, como señala Castells, porque sustituye un concepto de maximización real por otro que contiene valores subjetivos. Siguiendo con Castells, los mercados financieros están continuamente manipulados por estrategias de inversión generadas por ordenador, por percepciones 
subjetivas de análisis influyentes, por acontecimientos políticos y por turbulencias inesperadas provocadas por la volatilidad de flujos de capital en este sistema altamente no lineal.

El valor obsesivo por maximizar el precio de las acciones en el capitalismo lleva a las fusiones y adquisiciones de empresas, incluso a realizar adquisiciones hostiles. Las fusiones son buenas desde el punto de vista económico pero llevan a las personas a periodos de inestabilidad, turbulencia e incertidumbre que desencadenan en estrés; nuevamente nos encontramos con los efectos adversos de la globalización sobre el ser humano y su calidad de vida.

Como consecuencia de todos los efectos de la globalización descritos en párrafos precedentes, las economías grandes podrían asimilar y enfrentar las turbulencias con menos efectos adversos. En cambio, el mayor daño se estaría dando en las "economías emergentes" del margen, y no es en absoluto menos importante, al poner en riesgo el ecosistema y la subsistencia de las personas. La nueva economía ha incrementado nuestro impacto destructivo de la biósfera. Esta afirmación destacada por la ecologista Vandana Shiva implica que "el impacto de la inestabilidad climática y la destrucción de la capa de ozono recae sobre el Sur por su dependencia con la agricultura y materias primas ( ... ) la destrucción del medio natural va de la mano del desmantelamiento de los medios de vida tradicionales".

Se estima que hacia el 2060 el daño medioambiental provocado por la actividad económica será 200 veces mayor que el impacto actual. En conclusión, el Dr. Capra sostiene que el capitalismo global en su calidad presente es insostenible y necesita ser rediseñado desde sus raíces, además es ecológica y socialmente insostenible en el largo plazo, por lo tanto inviable.

En el libro se indica que al enumerar las tecnologías del siglo XX debemos incluir la "biotecnología" e "ingeniería genética", que no es lo mismo que la tecnología de la información genética. La ingeniería genética es una técnica que permite transferir genes entre diferentes organismos (genes de humanos en animales) y la ciencia de la genética culminó con el descubrimiento del ADN. El avance de la tecnología en genética logró que en los años noventa se obtuviera la clonación de animales con la biotecnología animal y también en el área de la agricultura se dieran grandes descubrimientos con la biotecnología vegetal; sin embargo, nuevamente, el auge del capitalismo global y el deseo de maximizar el precio de las acciones ha comprometido la ética de empresas de biotecnología que también son grandes corporaciones. 
Las empresas de biotecnología, para justificarse, argumentan que existe el determinismo genético para explicar enfermedades como el cáncer, la diabetes o la esquizofrenia, sin tomar en cuenta el impacto sobre las vidas humanas de factores sociales y ambientales que inciden sobre estas enfermedades.

El determinismo genético ha condicionado el debate público sobre la "clonación". Los cuestionamientos éticos reales sobre la clonación resultan claras a la luz de la comprensión de manipulaciones genéticas en las prácticas actuales, así como las motivaciones que los inspiran.

Los verdaderos problemas éticos de la clonación tienen sus raíces en los problemas biológicos de desarrollo que suscitan, dejando de lado si es ético o no destruir tantos embriones en nombre de la ciencia. Está absolutamente claro que la clonación de humanos sería totalmente inmoral e inaceptable, incluso la clonación de animales es cuestionada por la ética y por la sociedad civil en general.

La aplicación de la ingeniería genética en la agricultura tiene mayor resistencia y oposición que entre los animales, por la degradación del medio ambiente y el impacto ecológico al ecosistema. La agricultura química no ha ayudado ni a la tierra ni a los consumidores. La industria agroquímica persuadió a los agricultores que la aplicación de fertilizantes y productos químicos les traería mucho más dinero. Pero fueron "víctimas de la revolución verde", y los agricultores tuvieron que dejar sus tierras y migrar a las ciudades por la polución de las tierras y la infertilidad de las mismas.

Las plantaciones de Genética Modificada (GM) están creando las precondiciones clásicas para el hambre y la miseria; la concentración de las tierras en unos pocos es una amenaza para la seguridad alimentaria. La solución que encuentra el autor existía ya en la antigüedad, y se trata de la "agricultura ecológica", "agricultura sostenible" o "agroecología”. Ésta consiste en el cultivo mediante tecnologías que no se basan en la química o en la biotecnología, sino en el "conocimiento ecológico".

En este párrafo sintetizaré nuevamente los efectos negativos de la nueva economía global que resalta el Dr. Capra, y que provocan "desigualdades, discriminación, incremento de la pobreza y efectos al ecosistema totalmente adversos y con la biotecnología mal concebida se ha profanado al santuario de la vida al convertir la biodiversidad en monocultivo, la ecología en ingeniería y la propia vida en mercancía" (pág. 264). A pesar de las regulaciones medioambientales, persiste la pérdida masiva de bosques y la extinción de varias especies; 
al disminuir la biodiversidad y los recursos naturales ponemos en riesgo la supervivencia de nuestras vidas. Estos peligros se han exacerbado con el cambio climático producido por el sistema industrial

Coincido con el autor en que los valores de la dignidad humana y de la sostenibilidad ecológica constituyen la base de la ética para reorganizar la globalización. Finalmente, el Dr. Capra narra en su libro el surgimiento de la Coalición de Seattle, un movimiento bien coordinado que nace como una manifestación el 30 de noviembre de 1999 en contra del congreso del OMC y, por supuesto, en contra de la globalización. En enero de 2001 la Coalición de Seattle celebró el primer foro social mundial en Porto Alegre, Brasil, diseñado como contrapunto al foro económico mundial de Davos, en Suiza. El contraste fue total: en Brasil eran doce mil personas y en Suiza unos pocos; por primera vez la coalición de Seattle había convocado a sus miembros no solo para protestar sino para debatir sobre escenarios alternativos, de acuerdo con el lema del foro: "otro mundo es posible".

Con la Coalición de Seattle se tipifica un nuevo movimiento político y se crean numerosas ONGs cuyo mecanismo de comunicación es la internet, aprovechando la era de la información; por tanto, surge una nueva sociedad civil organizada en torno a la reconducción de la globalización que rechaza el patriarcado, la dominación y el control de la naturaleza; se trata de un rechazo a los valores de esta sociedad y de las instituciones tradicionales. Esta nueva sociedad civil se manifiesta en numerosas organizaciones no gubernamentales y en movimientos políticos que se apoyan en una red de intelectuales, institutos de investigación, bancos de pensadores y centros de aprendizaje que operan al margen de las instituciones académicas.

La mayoría de estos institutos promueven proyectos con tres agendas principales:

5. el desafío de remodelar las reglas e instituciones que gobiernan la globalización.

6. la oposición a los alimentos GM y la promoción de una agricultura sostenible.

7. el ecodiseño, que consiste en rediseñar nuestras estructuras físicas, nuestras ciudades, nuestras tecnologías y nuestras industrias para hacerlas ecológicamente sostenibles.

Las principales coaliciones de Seattle conformaron un Grupo de Estudio de Alternativas (GEA), bajo el liderazgo del Foro Internacional sobre la Globalización (FIG), para sintetizar ideas claves sobre alternativas para la nueva remodelación de la globalización económica 
vigente. El objetivo principal de estas propuestas consiste en la descentralización de poder de las instituciones globales, a favor de un sistema pluralista de organizaciones regionales e internacionales, cada una ellas monitoreada por organizaciones regionales; en suma, se trata de traspasar del poder global al poder regional.

El autor se adelanta al futuro cercano considerando el reemplazo de los organismos de Bretton Woods por nuevas alianzas de los países del Sur (denominados G77), por políticos favorables del Norte y por la nueva sociedad civil global, con suficiente fuerza para realizar reformas institucionales innovadoras y remodelar la globalización.

La propuesta central del autor se basa en dos alternativas para construir comunidades sostenibles:

1. "alfabetización ecológica", es decir, dotar de la capacidad para comprender los principios de organizaciones comunes a todos los sistemas vivos, entendiendo que los ecosistemas existen y han evolucionado desde el principio para sustentar la vida. (pág. 295).

2. "ecodiseño", que es el rediseño de nuestras tecnologías y de nuestras instituciones sociales, de manera que salvemos el abismo actual existente entre el diseño humano y los sistemas ecológicamente sostenibles de la naturaleza (pág. 294).

Asimismo, al finalizar el libro el autor nos habla de la organización ZERI, que implica cero emisiones y cero consumo de materiales que no sean renovables o tóxicos. La organización ZERI consiste en una red internacional de investigadores, empresarios, funcionarios gubernamentales y educadores. ZERI tiene en marcha 50 proyectos en el mundo y opera 25 centros en continentes, culturas y climas muy distintos (un ejemplo de centros de ZERI son los cafetales en Colombia).

Las agrupaciones ZERI son ejemplos claros de ecoalfabetización hecha ecodiseño. En una sociedad industrial sostenible todos los productos, materiales y residuos serán nutrientes biológicos o técnicos. Con la tecnología actual es perfectamente factible crear envoltorios que puedan ser arrojados al cubo del compost para su biodegradación (no deberíamos usar envases de champú, yogurt, cartones, etc., que duren más de lo que dura su contenido (incluso décadas o siglos). 
Desde la perspectiva del ecodiseño, el autor plantea que ya no existirán compra de bienes y productos, sino que se los alquilará del proveedor, y el nos cambiaría el producto por otro mejor con las mejoras tecnológicas (una especie de leasing); el fabricante reciclaría o desmontaría para obtener sus nutrientes técnicos y los utilizaría en su cadena de producción o los vendería a otros fabricantes. Esto implica el cambio de una economía orientada al producto y bienes por otra orientada al flujo y al servicio.

El ecodiseño implica que en los países subdesarrollados es posible reducir 90\% del consumo de energía y materiales; se conoce esto como el Factor Diez, porque consiste en multiplicar por diez la eficiencia de los recursos. Es posible tener edificios ecodiseñados que ahorran energía al dejar penetrar la luz natural y al mismo tiempo producen energía. Es posible crear "hipercoches", autos ultraligeros, supereficientes y no contaminantes, y es posible utilizar como única fuente de energía al sol (energía no renovable).

Todas estas alternativas y posibilidades que propone el autor son válidas y factibles; sin embargo, mi propuesta es contar con una tercera opción, que considero tan relevante como las otras dos, que consiste en la "alfabetización tecnológica", planteada en detalle durante el presente ensayo.

\section{Conclusión}

En el libro Las conexiones ocultas, del Dr. Capra, el autor vincula la evolución de la vida con el sistema de redes metabólicas, analiza a los sistemas vivos en sus cuatro perspectivas interconectadas: forma, materia, proceso y significado. Asimismo, explica que cada organismo no puede vivir aislado de su medio porque está estrechamente relacionado a él.

El autor conduce a la articulación del ser humano con las redes metabólicas, redes ecosistémicas, redes de comunicaciones y redes sociales, haciendo énfasis en la era de la información, que permite que las organizaciones estén estructuradas en estas redes sociales.

El rol del individuo en las estructuras de redes es fundamental por la dimensión social en que se proyecta y por las normas de conducta que rigen su comportamiento, enmarcadas dentro de su propia identidad cultural.

Los efectos negativos de la globalización se reflejan en el incremento de la pobreza, en la desigualdad social, en la discriminación, en el mercantilismo corporativo, que solo busca 
maximizar el valor de las acciones de las empresas, en el deterioro del ecosistema, y lo más preocupante, en la probable insostenibilidad ecológica y climática para la supervivencia de los seres vivos.

En este marco adverso se debe buscar alternativas de un nuevo orden económico social para maximizar el bienestar de los seres vivos y velar por la sostenibilidad y perpetuación de la especies, evitando su destrucción y el caos reflejado en plagas, enfermedades, huracanes, terremotos, maremotos, todos ellos producto del cambio climatológico; que está provocando la erosión de la tierra, la aniquilación de los bosques y la escasez de los recursos no renovables, concretamente, los recursos naturales.

Ante este panorama poco alentador de los efectos de la globalización, el autor plantea dos alternativas para generar una conciencia y sensibilización ecológica: la "alfabetización ecológica" y el "ecodiseño". La toma de consciencia es un aspecto clave en el nuevo entendimiento del esquema de la era de la información, de las comunicaciones y del progreso tecnológico.

El ensayo está focalizado concretamente en uno de los mayores efectos positivos que trajo consigo el fenómeno de la globalización, que es la innovación tecnológica, sin subestimar los efectos adversos ya descritos anteriormente. El desafío radica en el aprovechamiento inteligente de la tecnología para diseñar estrategias y políticas públicas en torno a la "alfabetización tecnológica", como una alternativa complementaria a la "alfabetización ecológica" y al "ecodiseño".

Debemos promover una política de concientización para aceptar un nuevo modelo económico-social alternativo e inclusivo, basado en la innovación tecnológica. Para ello se debe generar el diseño de políticas, estrategias y planes de acción concretos para beneficiar a la base de la pirámide social, que representa el $80 \%$ de la población mundial y que tan solo concentra solo el $15 \%$ de la riqueza.

En este contexto real, la "alfabetización tecnológica" permitirá buscar escenarios viables de solución frente al mayor efecto negativo de la globalización, que es la perpetuación de la pobreza a través de la generación de una brecha cada vez mayor entre países ricos y pobres, acentuando la ineficiente e inequitativa distribución de la riqueza en el mundo.

Se postula la generación de políticas públicas que afecten positivamente a la base de la pirámide social, para que gradualmente se acote la brecha existente entre ésta y la élite de la 
pirámide; el sistema educativo es esencial para lograr la alfabetización tecnológica, sobre todo en el nivel de la educación superior. Se debe cultivar la innovación tecnológica y plasmarla en emprendimientos tecnológicos medioambientales, ecológicos, sociales y productivos.

Se debe trabajar en las distintas disciplinas del conocimiento de manera coordinada para lograr un desarrollo transformacional que esté activamente presente en el imaginario del individuo y en su consciencia social. El desafío es que las universidades, como centros de generación y difusión de conocimiento, asuman su responsabilidad social universitaria (RSU) y reconduzcan la formación académica, considerando como principal herramienta la alfabetización tecnológica, que implica aprovechar la tecnología favorablemente para disminuir la pobreza en el mundo.

Las universidades deben focalizare en primer lugar en la innovación tecnológica profesionalizante, desarrollando emprendimientos sociales y productivos que proporcionen mecanismos yherramientas para lograrla accesibilidad a los recursos. Recordemos que la nueva concepción de la ciencia económica no es la escasez de los recursos sino su inaccesibilidad, y debería ser la "alfabetización tecnológica" el medio para lograr la accesibilidad a estos recursos, sobre todo, la accesibilidad para la base de la pirámide social.

El segundo foco, en absoluto menos importante, en el que deben concentrarse las universidades es en generar centros de debate, diálogo y postulación de propuestas de acción sobre el rol del ser humano como un todo integrador del ecosistema y como la pieza fundamental para expandir el conocimiento, adoptando sus propias normas de conducta relacionadas con su entorno personal, familiar, cultural y comunitario dentro de la sociedad.

Artículo recibido: 17 de septiembre de 2012 Aceptado: 10 de octubre de 2012 